\title{
EVI5 is a novel independent prognostic predictor in hepatocellular carcinoma after radical hepatectomy
}

\author{
JINTIAN TANG ${ }^{1,2^{*}}$, JIANGHUA OU ${ }^{3 *}$, CHUNYAN XU $^{1}$, CHAO YI $^{1}$, FENG XUE $^{1}$, LIN XU $^{1}$, \\ FENJU LAI ${ }^{4}$, JIANJUN TANG ${ }^{5}$, SHENGPING LI $^{6}$, TIEBANG KANG ${ }^{6}$, WEI DING ${ }^{1,2}$ and BOQING WANG ${ }^{1,2}$ \\ ${ }^{1}$ Department of Hepatopancreatobiliary Surgery, Affiliated Tumor Hospital of Xinjiang Medical University, Urumqi, Xinjiang; \\ ${ }^{2}$ Key Laboratory of Oncology in Xinjiang, Urumqi, Xinjiang; ${ }^{3}$ Department of Breast Surgery, Affiliated Tumor Hospital \\ of Xinjiang Medical University, Urumqi, Xinjiang; ${ }^{4}$ College of Bioscience and Engineering, Jiangxi Engineering \\ Laboratory for the Development and Utilization of Agricultural Microbial Resources, Jiangxi Agricultural University, \\ Nanchang, Jiangxi; ${ }^{5}$ Department of Gastroenterology, Cancer Hospital of Jiangxi Province, Nanchang, Jiangxi; ${ }^{6}$ State Key \\ Laboratory of Oncology in South China, Sun Yat-sen University Cancer Center, Guangzhou, Guangdong, P.R. China
}

Received February 12, 2017; Accepted July 21, 2017

DOI: $10.3892 / o r .2017 .5862$

\begin{abstract}
The present study explored the correlation of ecotropic viral integration site 5 (EVI5) expression with clinicopathological features and prognosis in hepatocellular carcinoma (HCC). A total of 205 HCC patients were included retrospectively. Quantitative real-time polymerase chain reaction (RT-qPCR) and western blotting were performed to detect the profile of EVI5 expression in HCC cell lines and fresh tissues. Archived paraffin-embedded specimens were investigated for EVI5 expression by immunohistochemistry (IHC). Both the mRNA and protein levels of EVI5 were obviously upregulated in HCC cell lines and tumor tissues. EVI5 protein level was closely associated with the clinicopathological characteristics, including liver function $(\mathrm{P}=0.013)$, venous invasion $(\mathrm{P}=0.015)$ and TNM stage $(\mathrm{P}=0.014)$. Furthermore, univariate analysis showed that the patients with high EVI5 expression indicated shorter overall survival (OS, $\mathrm{P}<0.001)$ and recurrence-free survival (RFS, $\mathrm{P}=0.001$ ) than those with low EVI5 expression. Importantly, high EVI5 expression also exerts predictive power for higher postoperative recurrence rate by stratified analysis. Multivariate Cox regression analysis demonstrated that OS was correlated with both tumor number $(\mathrm{P}=0.046)$ and EVI5 expression $(\mathrm{P}<0.001)$ and that RFS was correlated with serum AFP $(\mathrm{P}=0.023)$, tumor number
\end{abstract}

Correspondence to: Prof. Boqing Wang or Prof. Wei Ding, Department of Hepatopancreatobiliary Surgery, Affiliated Tumor Hospital of Xinjiang Medical University, 789 Suzhou East Street, Urumqi, Xinjiang Uygur Autonomous Region 830011, P.R. China E-mail: bqwanghps@163.com

E-mail: dingwei2@medmail.com.cn

Key words: hepatocellular carcinoma, ecotropic viral integration site 5, biomarker, hepatectomy, prognosis
$(\mathrm{P}=0.036)$ and EVI5 expression $(\mathrm{P}<0.001)$. Taken together, EVI5 is an useful independent prognostic marker of survival and recurrence in hepatocellular carcinoma.

\section{Introduction}

Hepatocellular carcinoma (HCC) is one of the deadliest malignancies worldwide. According to the data from the International Agency for Research on Cancer, more than half of global incidence (782000 estimated new cases) and mortality (746000 estimated deaths) were in China in 2012 (1). In recent years, the incidence and mortality of HCC have increased in the United States, while the incidence and mortality of HCC have declined in China $(2,3)$. Improvements in management and follow-up protocols seemly mean that they could provide additional benefit for HCC patients, whereas the 5-year overall survival rate still remained $\sim 30-40 \%$ in HCC. Currently, molecular targeted therapy has been used as a novel treatment in advanced HCC patients, but the effect is still suboptimal due to neoplastic heterogeneity. Therefore, it is necessary to identify optimal biomarkers for clinical treatment and prognostic assessment of $\mathrm{HCC}(4,5)$.

EVI5 (ecotropic viral integration site 5) is an 810 amino acid protein, which belongs to a small subfamily of the Tre-2/Bub2/ Cdc16 (TBC) domain-containing proteins. Earlier studies showed that EVI5 was expressed in various tissues, including in liver, brain, thymus and adrenal tissues (6). Many studies supported that EVI5 was a disease risk gene for multiple sclerosis $(7,8)$. In the field of cancer research, the studies of EVI5 are gaining attention. Functional study revealed that EVI5 played significant roles in cell cycle progression by interacting with Emi1 and Rab11 respectively, and that this regulation was also involved in vesicular trafficking and cytokinesis $(9,10)$. In addition, EVI5 protein associates with the INCENPaurora B kinase-survivin chromosomal passenger complex, facilitating the final stages of cell separation at the end of mitosis (11). Furthermore, it has been confirmed that EVI5 showed a close relationship with disease process in AKXD 
T-cell lymphomas (12). More importantly, EVI5 promoted the development of lymphomas by cooperating with the human BCL6 gene (13). All of above suggested that EVI5 plays a vital role in tumorigenesis.

During the past two decades, EVI5 has been recognized as a potential oncogene and a cell cycle regulator (14). However, it remains largely unclear between EVI5 and human cancers. In the present study, we investigated the prognostic significance of EVI5 expression in HCC.

\section{Materials and methods}

Cell lines and cell culture. Human normal liver cell line LO2 and seven hepatocellular carcinoma cell lines were cultured in this study. H2M and H2P were gifts from Professor Tiebang Kang laboratory (State Key Laboratory of Oncology in South China). HuH7, SMMC7721, BEL7402 and QGY7703 were purchased from the Shanghai Cell Bank Chinese Academy Sciences. HepG2 was purchased from the American Type Culture Collection (ATCC; Manassas, VA, USA). Cultured cells were maintained in Dulbecco's modified Eagle's medium ((DMEM; Invitrogen, Carlsbad, CA, USA) supplemented with $10 \%$ fetal bovine serum (FBS; Invitrogen), and incubated in a humidified atmosphere of 5\% $\mathrm{CO}_{2}$ at $37^{\circ} \mathrm{C}$.

Patient information and tissue specimens. A total of 205 consecutive patients who underwent radical hepatectomy between January 1, 2002 and December 31, 2004, at the Affiliated Tumor Hospital of Xinjiang Medical University were enrolled in the present study. Hepatectomy was carried out under general anesthesia using a right subcostal incision with a midline extension. Intraoperative ultrasound was routinely used. Radical hepatectomy was performed aiming at a surgical margin of at least $2 \mathrm{~cm}$. The clinicopathological information of the patients is listed in Table I. Paired fresh hepatocellular carcinoma tissues and adjacent non-tumor liver tissues were collected and processed within $30 \mathrm{~min}$ after resection. Each specimen was divided into two parts, one immediately preserved in liquid nitrogen for protein extraction, the other was immersed in RNAlater (Ambion, Inc., Austin, TX, USA) at $4^{\circ} \mathrm{C}$ overnight and then transferred to liquid nitrogen storage for RNA isolation. All patients were followed up and monitored prospectively, detailed methods including physical examination, serum $\alpha$-fetoprotein (AFP) and abdomen ultrasonography every 1-3 months in the first year, and every 3-6 months thereafter for surveillance of recurrence or metastases. For patients with test results suggestive of recurrence, contrast computed tomography and/or magnetic resonance imaging were used to verify whether recurrence had occurred. None of the patients combined with synchronous cancers, nor had undergone interventional therapy, chemotherapy or radiotherapy in the preoperation. Patients were staged according to the 7th edition of the American Joint Committee on Cancer (AJCC) tumor-node-metastasis (TNM) classification system. Overall survival (OS) was calculated from the day of hepatectomy to the day of death or to the date of the last follow-up. Recurrence-free survival (RFS) was defined as the interval from primary liver resection to the first recurrence. A diagnosis of recurrence was based on
Table I. Clinicopathological correlation of EVI5 expression in HCC patients.

\begin{tabular}{|c|c|c|c|c|}
\hline \multirow[b]{2}{*}{ Variables } & \multirow[b]{2}{*}{$\mathrm{N}$} & \multicolumn{2}{|c|}{$\begin{array}{l}\text { EVI5 expression } \\
(\mathrm{n}, \%)\end{array}$} & \multirow[b]{2}{*}{ P-value } \\
\hline & & Low & High & \\
\hline All cases & 205 & 112 & 93 & \\
\hline Age (years) & & & & 0.414 \\
\hline$\leq 50$ & $110(53.7)$ & $63(56.3)$ & $47(50.5)$ & \\
\hline$>50$ & $95(46.3)$ & $49(43.7)$ & $46(49.5)$ & \\
\hline Sex & & & & 0.698 \\
\hline Female & 24 (11.7) & $14(12.5)$ & $10(10.8)$ & \\
\hline Male & $181(88.3)$ & $98(87.5)$ & $83(89.2)$ & \\
\hline HBsAg & & & & 0.737 \\
\hline Negative & $26(12.7)$ & $15(13.4)$ & $11(11.8)$ & \\
\hline Positive & $179(87.3)$ & 97 (86.6) & $82(88.2)$ & \\
\hline Liver function & & & & 0.013 \\
\hline Child-Pugh A & $176(85.9)$ & $90(80.4)$ & $86(92.5)$ & \\
\hline Child-Pugh B & $29(14.1)$ & $22(19.6)$ & $7(7.5)$ & \\
\hline Serum AFP $(\mathrm{ng} / \mathrm{ml})$ & & & & 0.942 \\
\hline$\leq 25$ & $70(34.1)$ & 38 (33.9) & $32(34.4)$ & \\
\hline$>25$ & $135(65.9)$ & $74(66.1)$ & $61(65.6)$ & \\
\hline Tumor size $(\mathrm{cm})$ & & & & 0.632 \\
\hline$\leq 5$ & $160(78.0)$ & $86(76.8)$ & $74(79.6)$ & \\
\hline$>5$ & $45(22.0)$ & $26(23.2)$ & $19(20.4)$ & \\
\hline Tumor number & & & & 0.384 \\
\hline Solitary & $188(91.7)$ & $101(90.2)$ & $87(93.5)$ & \\
\hline Multiple & $17(8.3)$ & $11(9.8)$ & $6(6.5)$ & \\
\hline Venous invasion & & & & 0.015 \\
\hline Absent & $180(87.8)$ & $104(92.9)$ & $76(81.7)$ & \\
\hline Present & $25(12.2)$ & $8(7.1)$ & $17(18.3)$ & \\
\hline Histological grade & & & & 0.592 \\
\hline $\mathrm{I} / \mathrm{II}$ & $110(53.7)$ & $62(55.4)$ & $48(51.6)$ & \\
\hline $\mathrm{III} / \mathrm{IV}$ & $95(46.3)$ & $50(44.6)$ & $45(48.4)$ & \\
\hline TNM stage ${ }^{\mathrm{b}}$ & & & & 0.014 \\
\hline Stage I & $148(72.2)$ & $73(65.2)$ & 75 (80.6) & \\
\hline Stage II/III & $57(27.8)$ & $39(34.8)$ & $18(19.4)$ & \\
\hline
\end{tabular}

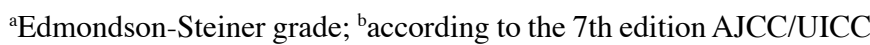
TNM stage system. HCC, hepatocellular carcinoma; HBsAg, hepatitis B surface antigen; AFP, $\alpha$-fetal protein; TNM, tumor-nodemetastasis; EVI5, ecotropic viral integration site 5. Bold, $\mathrm{P}<0.05$.

typical imaging appearance in computed tomography and/or magnetic resonance imaging scan and an elevated serum AFP level. For the use of these clinical materials for research purposes, prior written consent of the patients and approval from the Ethics Committee of the Affiliated Tumor Hospital of Xinjiang Medical University were obtained.

RNA extraction and quantitative real-time polymerase chain reaction $(R T-q P C R)$. The detailed protocol of this experiment 
was described in a previous study (15). Total RNA was isolated from cells and tissues using the TRIzol reagent (Invitrogen) according to the manufacturer's instruction, the mean yield rates were $150 \mu \mathrm{g}$ per $5 \times 10^{6}$ cells and $38 \mu \mathrm{g}$ per $10 \mathrm{mg}$ tissues, respectively. The first strand cDNA was generated using PrimeScript ${ }^{\circledR}$ RT reagent kit with gDNA Eraser (Takara Bio, Inc., Dalian, China). Subsequently, qPCR was conducted for detection of EVI5 mRNA using a SYBR-Green PCR kit (Takara Bio) and the CFX96 sequence detection system (Bio-Rad Laboratories, Inc., Hercules, CA, USA). Glyceraldehyde-3-phosphate dehydrogenase (GAPDH; forward: 5'-GGAGC GAGATCCCTCCAAAAT-3' and reverse, 5'-GGCTGTTGTC ATACTTCTCATGG-3') was used as the input control. The sequences of primers for EVI5 were as follows: forward, 5'-AGAAACCCTAGTGGGAAACAGG-3' and reverse, 5'-TG ACTGTATGCGATACTGTGTTC-3'. The $2^{-\Delta \Delta \mathrm{Ct}}$ method was used to analyze the relative change in EVI5 expression. The PCR condition was: $95^{\circ} \mathrm{C}$ for $10 \mathrm{~min}$, followed by 40 cycles of $95^{\circ} \mathrm{C}$ for $5 \mathrm{sec}$ and $60^{\circ} \mathrm{C}$ for $60 \mathrm{sec}$. Negative non-template control was also run on PCR.

Western blot assay. Western blotting was performed as previously described (15). In brief, specimens were ground to powder in liquid nitrogen, collected and lysed by RIPA buffer, centrifuged at $13,400 \mathrm{~g}$ for $30 \mathrm{~min}$ at $4^{\circ} \mathrm{C}$, and then heated at $95^{\circ} \mathrm{C}$ for $10 \mathrm{~min}$. Proteins ( $35 \mu \mathrm{g}$ per lane) were separated on $10 \%$ sodium dodecyl sulfate-polyacrylamide gradient gels, transferred onto PVDF membranes, and followed by blocking with $5 \%$ non-fat milk for $2 \mathrm{~h}$ at room temperature. Membranes were incubated with primary antibody and horseradish peroxidase-conjugated secondary antibody, and then detected by chemiluminesence using the enhanced chemiluminescence (ECL) system. Antibodies against EVI5 and $\beta$-actin were purchased from Santa Cruz Biotechnology (Santa Cruz, CA, USA; sc-160055, $0.2 \mathrm{mg} / \mathrm{ml}, 1: 200$ dilution) and Bioworld Technology (St. Louis Park, MN, USA; AP0060, $1 \mathrm{mg} / \mathrm{ml}$, 1:10,000 dilution), respectively.

Immunohistochemistry (IHC) and IHC evaluation. After hematoxylin and eosin (H\&E) staining, the degree of tumor differentiation was evaluated in terms of Edmondson-Steiner histological grading system. IHC was performed on hepatocellular carcinoma and paratumor tissues as previously described (15). Paraffin-embedded sections were deparaffinized, rehydrated and then prepared for antigen retrieval. Sections were blocked with $10 \%$ normal goat serum, incubated with primary antibody against EVI5 (Sigma-Aldrich, St. Louis, MO, USA; HPA027339, 1:100 dilution) at $4^{\circ} \mathrm{C}$ overnight in a moist chamber, and treated by biotin-labeled secondary antibody for $1 \mathrm{~h}$ at room temperature. Subsequently, the samples were developed by adding DAB (Genetech, Co., Ltd., Beijing, China) and counterstained with hematoxylin. The sections were reviewed and scored independently by two observers who were masked to clinicopathological materials, based on both the proportion of positively stained tumor cells and the staining intensity. The immunoreactions for EVI5 in cytoplasm was quantified, respectively, using widely accepted German semi-quantitative scoring system (16). The proportion of positive tumor cells was scored as follows: 0 , no positive tumor cells; $1,1-25 \% ; 2,26-50 \% ; 3,51-75 \%$; and 4 ,
76-100\%. The intensity of staining was categorized as follows: 0 , no staining; 1 , weak staining (light yellow); 2 , moderate staining (yellow brown); and 3, strong staining (brown). The staining index (SI) was calculated as staining intensity score multiplied by positive tumor cells percentage score (17). The range of SI was from 0 to 12 , and cut-offs were selected by the receiver operating characteristic (ROC) curve analysis. $\mathrm{SI}<6$ was defined as low EVI5 expression and $\mathrm{SI} \geq 6$ was defined as high EVI5 expression. Confirmed immunostaining-positive slides were used as positive controls. A rabbit polyclonal IgG antibody (ab27478; Abcam) replaced the primary antibody as a negative control.

Statistical analysis. The SPSS statistical software package (version 16.0; SPSS, Inc., Chicago, IL, USA) was used. The Pearson's Chi-square test was utilized to analyze the relationship between the EVI5 expression and the clinicopathological parameters. Survival curves were generated by the KaplanMeier method and compared by the log-rank test. Univariate analysis identified variables associated with survival, and than significant variables associated with survival in univariate analysis were entered into a multivariate Cox proportional hazard regression model. Finally, independent prognostic factors were determined. A two-sided $\mathrm{P}<0.05$ was considered to be statistically significant.

\section{Results}

EVI5 is overexpressed in HCC cell lines and clinical samples. To detect EVI5 expression profile, initially, multiple HCC cell lines were used to measure mRNA and protein expression levels of EVI5 by RT-qPCR and western blotting assay, respectively. Both the mRNA and protein levels of EVI5 were elevated in the $7 \mathrm{HCC}$ cell lines, including H2M, H2P, HuH7, SMMC7721, HepG2, BEL7402 and QGY7703, than those in LO2 (Fig. 1A and B). Among these cancer cell lines, EVI5 mRNA was almost 5-fold overexpressed in H2M compared to normal LO2 liver cells. Furthermore, by use of the fresh HCC specimens, we also observed that the expression of EVI5 mRNA were remarkably higher in 7 of 8 HCC tissues than that in the matched adjacent non-tumor liver tissues, which was consistent with corresponding paired protein levels (Fig. 1C and D). These results show that EVI5 is upregulated in HCC.

Correlation between EVI5 protein expression and HCC clinicopathological features. To further evaluate the relationship between the EVI5 protein expression and the clinicopathological characteristics of HCC, 205 paraffin-embedded HCC samples were detected by IHC. According to the cut-off value of 6 , all of patients could be divided into high-expression group $(45.4 \%, 93 / 205)$ and low-expression group $(54.6 \%$, 112/205). Chi-square test indicated that the EVI5 protein level was closely associated with some of the clinicopathological variables of HCC, including liver function $(\mathrm{P}=0.013)$, venous invasion $(\mathrm{P}=0.015)$ and TNM stage $(\mathrm{P}=0.014)$. However, EVI5 protein expression is unrelated to age, sex, hepatitis $\mathrm{B}$ surface antigen (HBs Ag), serum AFP, tumor size, tumor number and histological grade (Table I). Moreover, patients in the venous invasion group $(68.0 \%, 17 / 25)$ had a greater proportion of 


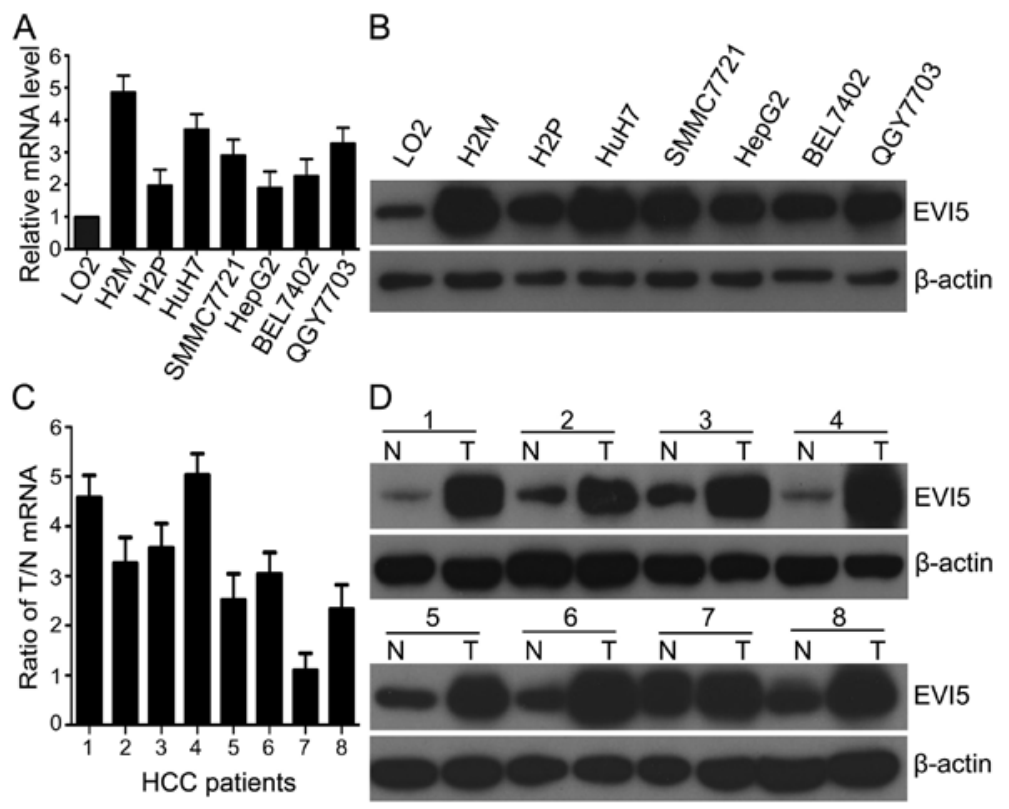

Figure 1. Expression of EVI5 in HCC cell lines and tissue samples. (A) The mRNA levels of EVI5 in immobilized liver cell line (LO2) and HCC cell lines were determined using RT-qPCR. (B) Representative pattern of EVI5 protein expressed in cell lines are shown. (C and D) Eight pairs of HCC T (tumor) tissues and their NT (non-tumor) counterparts were examined by RT-qPCR and western blotting. Relative mRNA (C) and protein (D) levels of EVI5 were upregulated in HCC clinical samples.

Table II. Univariate prognostic analysis of overall survival and recurrence-free survival rates for 205 surgical HCC patients.

\begin{tabular}{|c|c|c|c|c|}
\hline \multirow[b]{2}{*}{ Variables } & \multicolumn{2}{|c|}{ Overall survival } & \multicolumn{2}{|c|}{ Recurrence-free survival } \\
\hline & $\mathrm{HR}(95 \% \mathrm{CI})$ & P-value & $\mathrm{HR}(95 \% \mathrm{CI})$ & P-value \\
\hline Age, years ( $\leq 50$ vs. $>50)$ & $1.359(0.943-1.960)$ & 0.100 & $1.267(0.908-1.767)$ & 0.163 \\
\hline Sex (female vs. male) & $1.122(0.630-1.998)$ & 0.696 & $1.368(0.787-2.378)$ & 0.267 \\
\hline HBsAg (negative vs. positive) & $1.095(0.626-1.916)$ & 0.750 & $1.183(0.703-1.994)$ & 0.527 \\
\hline Serum AFP, ng/ml ( $\leq 25$ vs. $>25)$ & $1.548(1.032-2.320)$ & 0.034 & $1.771(1.221-2.568)$ & 0.003 \\
\hline Liver function (Child-Pugh A vs. B) & $1.008(0.699-1.454)$ & 0.965 & $0.891(0.638-1.242)$ & 0.495 \\
\hline Histological grade ${ }^{a}$ (I/II vs. III/IV) & $1.511(1.048-2.179)$ & 0.027 & $1.669(1.195-2.331)$ & 0.003 \\
\hline Tumor number (solitary vs. multiple) & $2.190(1.201-3.994)$ & 0.011 & $2.143(1.223-3.755)$ & 0.008 \\
\hline Tumor size, $\mathrm{cm}(\leq 5 \mathrm{vs} .>5)$ & $1.655(1.090-2.513)$ & 0.018 & $1.740(1.189-2.546)$ & 0.004 \\
\hline Venous invasion (absent vs. present) & $2.366(1.467-3.814)$ & 0.000 & $2.341(1.474-3.718)$ & 0.000 \\
\hline TNM stage ${ }^{\mathrm{b}}$ (I vs. II/III) & $1.550(1.205-1.992)$ & 0.001 & $1.505(1.040-2.170)$ & 0.028 \\
\hline EVI5 expression (low vs. high) & $1.903(1.316-2.751)$ & 0.001 & $1.706(1.221-2.383)$ & 0.002 \\
\hline
\end{tabular}

${ }^{a}$ Edmondson-Steiner grade. ${ }^{b}$ According to the 7th edition AJCC/UICC TNM stage system. HCC, hepatocellular carcinoma; HBsAg, hepatitis B surface antigen; CI, confidence interval; HR, hazard ratio; AFP, $\alpha$-fetal protein; TNM, tumor-node-metastasis; EVI5, ecotropic viral integration site 5. Bold, $\mathrm{P}<0.05$.

high EVI5 expression, compared with those in the absence of venous invasion group $(42.2 \%, 76 / 180)$.

Association between EVI5 expression and HCC survival. Among this retrospective cohort of $205 \mathrm{HCC}$ cases, including 148 cases of stage I (72.2\%), 32 cases of stage II (15.6\%), 25 cases of stage III (12.2\%), IHC was conducted to explore the expression pattern of EVI5. The immunostaining of EVI5 was stronger in HCC than in matched adjacent non-tumor tissue (Fig. 2A and B). The staining intensity was classified into four grades (negative, score $=0$; weak, score $=1$; moderate, score $=2$; strong, score $=3$ ) $($ Fig. $2 \mathrm{C}-\mathrm{F})$. The positive staining predominantly localized in the cytoplasm.

The EVI5 protein level was negatively correlated with overall survival (OS, $\mathrm{P}<0.001$; Fig. 3A) and recurrence-free survival (RFS, $\mathrm{P}=0.001$; Fig. $3 \mathrm{~B}$ ). The patients with low EVI5 expression in HCC tumor tissue had better OS and RFS rates than those with high EVI5 expression. The overall 3- and 5-year cumulative survival rate of patients with high EVI5 expression were 62.3 and $39.1 \%$. For those with low EVI5 expression, the rates were 68.5 and $54.1 \%$ (Fig. 3A). The recurrence-free survival (RFS) rate at 3- and 5-year were 61.3 and $38.6 \%$ 
Table III. Cox multivariate regression analysis on overall survival and recurrence-free survival in 205 HCC patients after hepatectomy.

\begin{tabular}{|c|c|c|c|c|}
\hline \multirow[b]{2}{*}{ Variables } & \multicolumn{2}{|c|}{ Overall survival } & \multicolumn{2}{|c|}{ Recurrence-free survival } \\
\hline & $\mathrm{HR}(95 \% \mathrm{CI})$ & P-value & $\mathrm{HR}(95 \% \mathrm{CI})$ & P-value \\
\hline Serum AFP ng/ml ( $\leq 25$ vs. $>25)$ & $1.378(0.892-2.130)$ & 0.149 & $1.577(1.066-2.333)$ & 0.023 \\
\hline Histological grade $^{\text {a }}$ (I/II vs. III/IV) & $1.356(0.917-2.005)$ & 0.127 & $1.570(0.826-2.984)$ & 0.169 \\
\hline Tumor number (solitary vs. multiple) & $1.992(1.011-3.925)$ & 0.046 & $1.467(1.026-2.099)$ & 0.036 \\
\hline Tumor size, $\mathrm{cm}(\leq 5$ vs. $>5)$ & $1.324(0.764-2.294)$ & 0.318 & $1.512(0.921-2.483)$ & 0.102 \\
\hline Venous invasion (absent vs. present) & $1.255(0.668-2.360)$ & 0.480 & $1.191(0.671-2.111)$ & 0.551 \\
\hline TNM stage $^{\mathrm{b}}$ (I vs. II /III) & $1.155(0.673-1.983)$ & 0.600 & $1.236(0.754-2.027)$ & 0.401 \\
\hline EVI5 expression (low vs. high) & $2.141(1.437-3.190)$ & 0.000 & $1.903(1.334-2.715)$ & 0.000 \\
\hline
\end{tabular}

${ }^{a}$ Edmondson-Steiner grade. ${ }^{b}$ According to the 7th edition AJCC/UICC TNM stage system. HCC, hepatocellular carcinoma; CI, confidence interval; HR, hazard ratio; AFP, $\alpha$-fetal protein; TNM, tumor-node-metastasis; EVI5, ecotropic viral integration site 5. Bold, P<0.05.
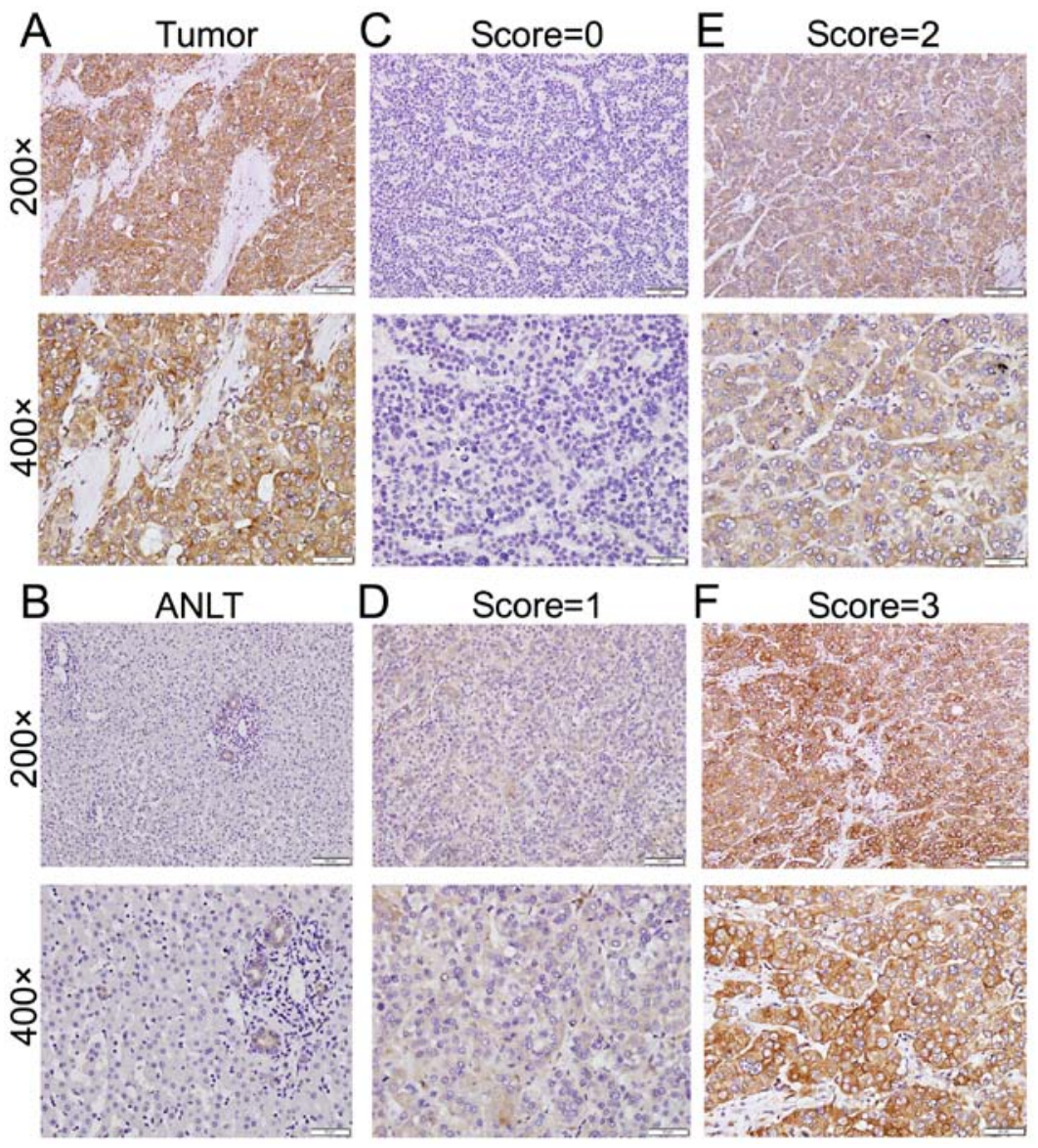

Figure 2. Expression of EVI5 in HCC and adjacent non-tumor tissues by IHC. EVI5 staining was observed mainly localized within the cytoplasm. (A) Positive EVI5 staining in tumor tissue. (B) Negative EVI5 staining in adjacent non-tumor liver tissue (ANLT). (C-F). The intensities of EVI5 staining in HCC were scored as four grades $(0,1,2$ and 3), respectively as indicated. Magnification, x200 and x400.

for high EVI5 expression subjects compared with 70.3 and 49.9\% for low EVI5 expression ones, respectively (Fig. 3B). According to the following-up data analysis, EVI5 highexpression group had a shorter overall survival time (median OS, 39.0 months) and recurrence-free survival time (median RFS, 15.0 months) compared with the low-expression group (median OS, 63.0 months; median RFS, 30.0 months).
Univariate analysis revealed there were 7 risk factors associated with OS and RFS, respectively (Table II). Moreover, Cox regression analysis demonstrated that EVI5 expression was an independent prognostic factor for OS in HCC patients as well as tumor number. Independent prognostic factors for RFS including EVI5 expression, tumor number and serum AFP (Table III). 

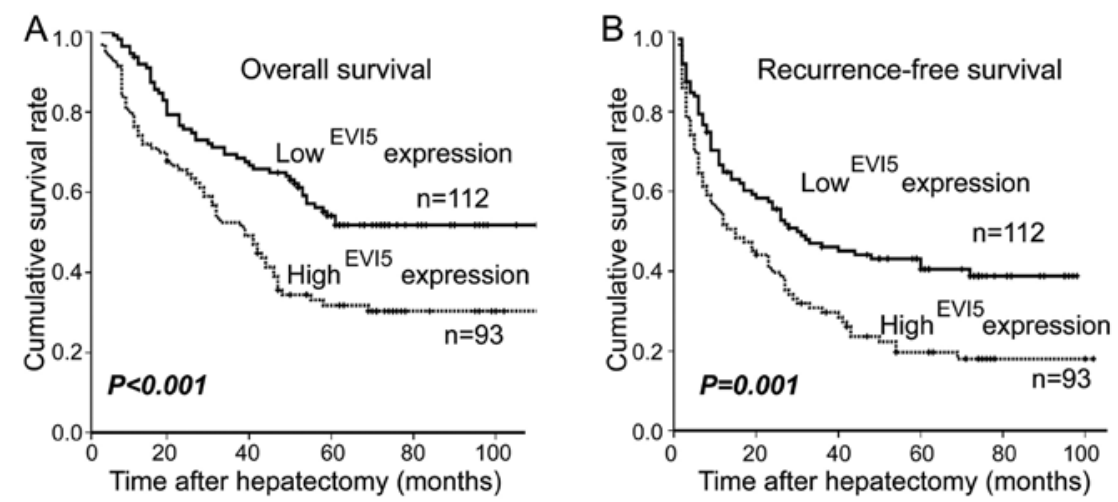

Figure 3. Correlation of EVI5 expression in 205 HCC patients with overall survival (A) and recurrence-free survival (B). Kaplan-Meier survival analysis (log-rank test) demonstrated that high EVI5 expression indicated unfavorable OS and RFS.
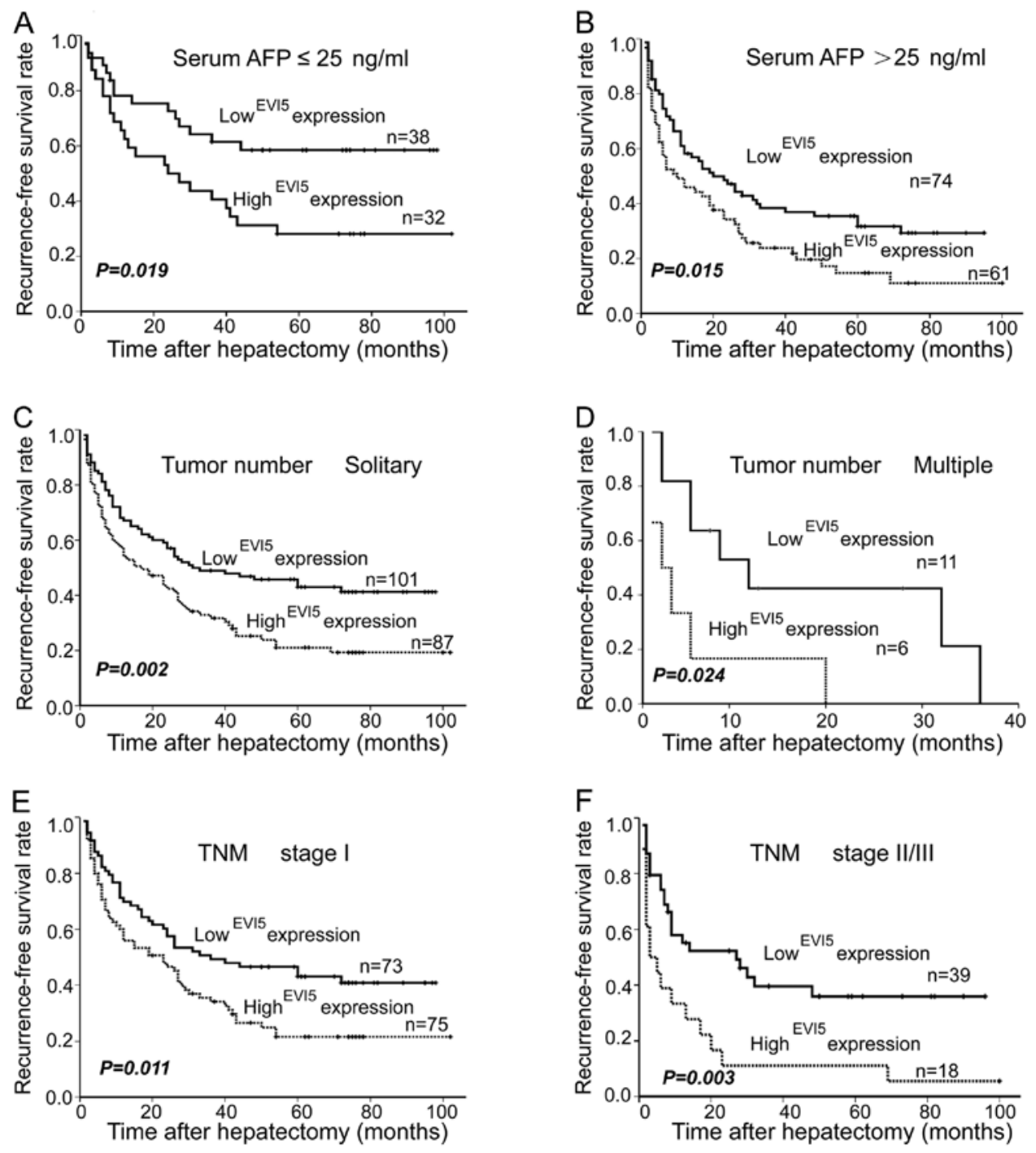

Figure 4. Association of EVI5 expression with recurrence-free survival in HCC subgroups. Survival analysis was performed according to the factors that were contributed to tumor recurrence, (A and B) serum AFP, (C and D) tumor number, (E and F) TNM stage. Kaplan-Meier stratified survival analysis was used (log-rank test).

Furthermore, based on the analysis of the 3 subgroups, the influence of EVI5 expression on postoperative recurrence was further revealed by stratified analysis. As shown in Fig. 4, high EVI5 expression exhibited short-term recurrence in the serum
AFP subgroup (Fig. 4A, P=0.019; Fig. 4B, P=0.015). Similarly, whether the patients had a solitary tumor or multiple tumors, the patients with high EVI5 expression were associated with significantly worse RFS (Fig. 4C, $\mathrm{P}=0.002$; Fig. 4D, $\mathrm{P}=0.024$ ). 
Additionally, in TNM subgroup, high EVI5 expression was confirmed as an unfavorable factor once again, and this meant that high EVI5 expression contributed to shorter RFS under the same TNM stage (Fig. 4E, $\mathrm{P}=0.011$; Fig. 4F, $\mathrm{P}=0.003$ ). Thus, EVI5 is a valuable prognostic marker for HCC patients.

\section{Discussion}

Hepatocellular carcinoma (HCC) which is one of the most common malignant tumors worldwide, it is a serious threat to human health and survival. In recent years, the studies focusing on tumor molecular biomarkers seemed to provide new insight into diagnosis, treatment and prognostic assessment for precise medicine. Therefore, it is significant to identify sensitive and specific biomarkers for HCC. Here, we identified and validated EVI5 as a novel prognostic biomarker for HCC.

Previous studies show that EVI5 was located in the nucleus and cytoplasm $(18,19)$. But interestingly, we failed to observe a clear and specific nuclear staining within tumor cells. Thus, we scored only for cytoplastic staining status. In recent years, an increasing number of reports have linked EVI5 to various human neoplasms, such as HCC (20), bladder cancer (21), melanoma (22), leukemogenesis (23) and lymphomas (13).

In the initial studies, EVI5 participated in regulation of cell cycle in different compartments of cell, functioned by stabilizing the Emil protein and promoting cyclin-A accumulation, EVI5 misregulation led to abnormity of cell cycle and cell division (24). Investigation found that EVI5 levels were significantly increased during the formation of embryo limb regeneration in newts (25). Furthermore, EVI5 widely participated in various regulatory functions, including cell fate determination (26), autophagy (27), membrane trafficking and cytokinesis (28), cell migration $(29,30,32)$, as well as growth and differentiation of cells (31). In general, prior studies indicated that EVI5 can function as an onco-protein which might promote malignant phenotype of cancer cells.

Our results support the above previous findings. We showed that EVI5 protein overexpressed in HCC cell lines and tumor tissues compared with normal liver cell line (LO2) and corresponding paratumor tissues. Furthermore, we validated the differential expression by RT-qPCR and IHC. In particular, a pair of cell models, from heptic portal vein tumor thrombus (H2M) and primary tumor (H2P) (33), helped explore metastatic mechanism in HCC. Notably, we found that the expression of EVI5 in H2M was much higher than that in $\mathrm{H} 2 \mathrm{P}$, which supported that EVI5 was involved in the metastasis of HCC. However, much work should be done to unveil the detailed mechanism in future. The study of Li et al (20) have revealed that HSF1/miR-135b/RECK\&EVI5 axis may be related to the mechanism of metastasis in HCC. These results indicated that EVI5 behaved as a regulator in tumorigenesis and metastasis.

Chi-square analysis demonstrated that EVI5 expression level was correlated with serum AFP, tumor number and TNM stage. Among TNM stages, the lower percentage of high EVI5 in advanced stage II/III (19.4\%) than stage I $(80.6 \%)$, may be due to fewer subjects with stage II/III $(57 / 205,27.8 \%)$. Interestingly, we still found the high EVI5 expression tended to occur in sufferers with more advanced stage (stage II, $25.0 \%$ vs. stage III, $40.0 \%$ ), suggesting that EVI5 might be involved in tumor progression. Kaplan-Meier analysis showed that the OS and RFS curves were significantly separated between two cohorts with different EVI5 expression. The high expression of EVI5 was associated with shorter OS and RFS, low expression group showed contrary results. Tumor relapse is a key cause for therapeutic failure. Therefore, we investigated the prognostic factors that attributed to recurrence by stratified analysis. Cox regression analysis showed that serum AFP, tumor number and EVI5 expression were independent prognostic factors. TNM stage was failed to be selected, which may be due to fewer advanced patients (TNM stage II/III, 27.8\%). Subgroup analysis demonstrated that among these patients with lower serum AFP, solitary or TNM stage I, high EVI5 expression was consistently associated with shorter RFS, which means that these patients could be distinguished for early intervention to prevent tumor recurrence. To those patients with EVI5 high expression, accompanying with high serum AFP, multiple or advanced stages, comprehensive treatment strategy should be considered as soon as possible.

In conclusion, our findings showed that the EVI5 was upregulated in HCC. The high expression of EVI5 indicated a worse prognosis in postoperative HCC subjects. EVI5 is a novel predictive biomarker that may help guide the clinical therapy for HCC patients.

\section{Acknowledgements}

The present study was supported by grants from the National Natural Science Foundation in China (grant no. 81460360 to B.W. and grant no. 81560403 to J.T.); the Natural Science Foundation of Xinjiang Uygur Autonomous Region, (grant no. 2015211C126 to B.W. and grant no. 2016D01C374 to J.T.). The authors thank professor Tiebang Kang of Sun Yat-sen University Cancer Center for providing experimental platform and expert opinions.

\section{References}

1. Torre LA, Bray F, Siegel RL, Ferlay J, Lortet-Tieulent J and Jemal A: Global cancer statistics, 2012. CA Cancer J Clin 65: 87-108, 2015.

2. Siegel RL, Miller KD and Jemal A: Cancer statistics, 2015. CA Cancer J Clin 65: 5-29, 2015.

3. Chen W, Zheng R, Baade PD, Zhang S, Zeng H, Bray F, Jemal A, Yu XQ and He J: Cancer statistics in China, 2015. CA Cancer J Clin 66: 115-132, 2016.

4. Chen S, Ling Q, Yu K, Huang C, Li N, Zheng J, Bao S, Cheng Q, Zhu $\mathrm{M}$ and Chen M: Dual oxidase 1: A predictive tool for the prognosis of hepatocellular carcinoma patients. Oncol Rep 35: 3198-3208, 2016.

5. Wu Y, Lin X, Di X, Chen Y, Zhao H and Wang X: Oncogenic function of Placl on the proliferation and metastasis in hepatocellular carcinoma cells. Oncol Rep 37: 465-473, 2017.

6. Roberts T, Chernova $\mathrm{O}$ and Cowell JK: NB4S, a member of the TBC1 domain family of genes, is truncated as a result of a constitutional $\mathrm{t}(1 ; 10)(\mathrm{p} 22 ; \mathrm{q} 21)$ chromosome translocation in a patient with stage 4S neuroblastoma. Hum Mol Genet 7: 1169-1178, 1998.

7. Didonna A, Isobe N, Caillier SJ, Li KH, Burlingame AL, Hauser SL, Baranzini SE, Patsopoulos NA and Oksenberg JR: A non-synonymous single-nucleotide polymorphism associated with multiple sclerosis risk affects the EVI5 interactome. Hum Mol Genet 24: 7151-7158, 2015. 
8. Liu J, Liu X, Liu Y, Deng S, Huang H, Chen Q, Liu W and Huang Z: Association of EVI5 rs11808092, CD58 rs2300747, and CIITA rs3087456 polymorphisms with multiple sclerosis risk: A meta-analysis. Meta Gene 9: 97-103, 2016.

9. Westlake CJ, Junutula JR, Simon GC, Pilli M, Prekeris R, Scheller RH, Jackson PK and Eldridge AG: Identification of Rab11 as a small GTPase binding protein for the Evi5 oncogene. Proc Natl Acad Sci USA 104: 1236-1241, 2007.

10. Eldridge AG, Loktev AV, Hansen DV, Verschuren EW, Reimann JD and Jackson PK: The evi5 oncogene regulates cyclin accumulation by stabilizing the anaphase-promoting complex inhibitor emi1. Cell 124: 367-380, 2006.

11. Faitar SL, Sossey-Alaoui K, Ranalli TA and Cowell JK: EVI5 protein associates with the INCENP-aurora B kinase-survivin chromosomal passenger complex and is involved in the completion of cytokinesis. Exp Cell Res 312: 2325-2335, 2006

12. Liao X, Buchberg AM, Jenkins NA and Copeland NG: Evi-5, a common site of retroviral integration in AKXD T-cell lymphomas, maps near Gfi-1 on mouse chromosome 5. J Virol 69: 7132-7137, 1995 .

13. Baron BW, Anastasi J, Bies J, Reddy PL, Joseph L, Thirman MJ, Wroblewski K, Wolff L and Baron JM: GFI1B, EVI5, MYB - additional genes that cooperate with the human BCL6 gene to promote the development of lymphomas. Blood Cells Mol Dis 52: 68-75, 2014.

14. Heber-Katz E, Zhang Y, Bedelbaeva K, Song F, Chen X and Stocum DL: Cell cycle regulation and regeneration. Curr Top Microbiol Immunol 367: 253-276, 2013.

15. Wang B, Tang J, Liao D, Wang G, Zhang M, Sang Y, Cao J, Wu Y, Zhang R, Li S, et al: Chromobox homolog 4 is correlated with prognosis and tumor cell growth in hepatocellular carcinoma. Ann Surg Oncol 20 (Suppl 3): S684-S692, 2013.

16. Henriksen KL, Rasmussen BB, Lykkesfeldt AE, Møller S, Ejlertsen B and Mouridsen HT: Semi-quantitative scoring of potentially predictive markers for endocrine treatment of breast cancer: A comparison between whole sections and tissue microarrays. J Clin Pathol 60: 397-404, 2007.

17. Liao WT, Guo L, Zhong Y, Wu YH, Li J and Song LB: Astrocyte elevated gene-1 (AEG-1) is a marker for aggressive salivary gland carcinoma. J Transl Med 9: 205, 2011.

18. Faitar SL, Dabbeekeh JT, Ranalli TA and Cowell JK: EVI5 is a novel centrosomal protein that binds to alpha- and gamma-tubulin. Genomics 86: 594-605, 2005.

19. Fuchs E, Haas AK, Spooner RA, Yoshimura S, Lord JM and Barr FA: Specific Rab GTPase-activating proteins define the Shiga toxin and epidermal growth factor uptake pathways. J Cell Biol 177: 1133-1143, 2007.

20. Li Y, Xu D, Bao C, Zhang Y, Chen D, Zhao F, Ding J, Liang L, Wang Q, Liu L, et al: MicroRNA-135b, a HSF1 target, promotes tumor invasion and metastasis by regulating RECK and EVI5 in hepatocellular carcinoma. Oncotarget 6: 2421-2433, 2015.

21. Scaravilli M, Asero P, Tammela TL, Visakorpi $T$ and Saramäki OR: Mapping of the chromosomal amplification 1p21-22 in bladder cancer. BMC Res Notes 7: 547, 2014.
22. Varghese $\mathrm{S}, \mathrm{Xu} \mathrm{H}$, Bartlett $\mathrm{D}$, Hughes $\mathrm{M}$, Pingpank JF, Beresnev T and Alexander HR Jr: Isolated hepatic perfusion with high-dose melphalan results in immediate alterations in tumor gene expression in patients with metastatic ocular melanoma. Ann Surg Oncol 17: 1870-1877, 2010.

23. Jacob B, Osato M, Yamashita N, Wang CQ, Taniuchi I, Littman DR, Asou N and Ito Y: Stem cell exhaustion due to Runx 1 deficiency is prevented by Evi5 activation in leukemogenesis. Blood 115: 1610-1620, 2010

24. Verschuren EW, Ban KH, Masek MA, Lehman NL and Jackson PK: Loss of Emil-dependent anaphase-promoting complex/cyclosome inhibition deregulates E2F target expression and elicits DNA damage-induced senescence. Mol Cell Biol 27: 7955-7965, 2007.

25. Rao N, Jhamb D, Milner DJ, Li B, Song F, Wang M, Voss SR, Palakal M, King MW, Saranjami B, et al: Proteomic analysis of blastema formation in regenerating axolotl limbs. BMC Biol 7: 83, 2009.

26. Emery G, Hutterer A, Berdnik D, Mayer B, Wirtz-Peitz F, Gaitan MG and Knoblich JA: Asymmetric Rab 11 endosomes regulate delta recycling and specify cell fate in the Drosophila nervous system. Cell 122: 763-773, 2005.

27. Longatti A, Lamb CA, Razi M, Yoshimura S, Barr FA and Tooze SA: TBC1D14 regulates autophagosome formation via Rab11- and ULK1-positive recycling endosomes. J Cell Biol 197: 659-675, 2012

28. Giansanti MG, Belloni G and Gatti M: Rab11 is required for membrane trafficking and actomyosin ring constriction in meiotic cytokinesis of Drosophila males. Mol Biol Cell 18: 5034-5047, 2007.

29. Kawauchi T, Sekine K, Shikanai M, Chihama K, Tomita K, Kubo K, Nakajima K, Nabeshima Y and Hoshino M: Rab GTPases-dependent endocytic pathways regulate neuronal migration and maturation through $\mathrm{N}$-cadherin trafficking. Neuron 67: 588-602, 2010.

30. Kessler D, Gruen GC, Heider D, Morgner J, Reis H, Schmid KW and Jendrossek V: The action of small GTPases Rab11 and Rab25 in vesicle trafficking during cell migration. Cell Physiol Biochem 29: 647-656, 2012

31. Liao X, Du Y, Morse HC III, Jenkins NA and Copeland NG: Proviral integrations at the Evi5 locus disrupt a novel $90 \mathrm{kDa}$ protein with homology to the Tre 2 oncogene and cell-cycle regulatory proteins. Oncogene 14: 1023-1029, 1997.

32. Laflamme C, Assaker G, Ramel D, Dorn JF, She D, Maddox PS and Emery G: Evi5 promotes collective cell migration through its Rab-GAP activity. J Cell Biol 198: 57-67, 2012.

33. Hu L, Wen JM, Sham JS, Wang W, Xie D, Tjia WM, Huang JF, Zhang M, Zeng WF and Guan XY: Establishment of cell lines from a primary hepatocellular carcinoma and its metastatis. Cancer Genet Cytogenet 148: 80-84, 2004. 